\title{
Low energy, but lots of loot in UK forecast
}

Energy needs in the UK in the year 2000 will be at most $3 \%$ more than in 1976, and may even be $6 \%$ less, according to a report published by the International Institute for the Environment and Development last week. The report emphasises the savings that can be made by introducing proven conservation technologies, and allows for a trebling of Britain's gross domestic product (GDP). In contrast, the present official forecast of the Department of Energy (DOEn) projects an energy growth of some $35 \%$ to $70 \%$ by 2000 after allowing for a $20 \%$ saving through conservation measures.

The IIED forecast may nevertheless not be extreme. The DOEn admitted last week that their $20 \%$ conservation figure was a rough one, and said that they had been waiting for nearly a year for a response to it. Their figure was based on consumer research by the Electricity Council and the Gas Boards, advice from the Department of the Environment on the progress of insulation of buildings, "and many other sources", but was open to revision. The IIED report would have its impact on the forthcoming Green Paper on energy futures, said a spokesman, although there was too little time to take it fully into account.

Mr Gerald Leach, the author of the

A low energy strategy for the UK (Science Reviews Ltd and IIED) $£ 7.50$. Obtainable from IIED, 10 Percy Street, London W1.

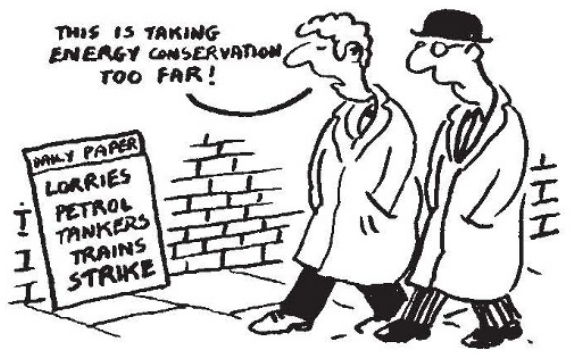

report, said last week that far from having an energy gap the UK had "a great deal of room to manoeuvre on supply options, without extreme measures". Much of the necessary conservation technology - such as heat pumps for domestic space heating and efficient internal combustion engineswill become available in the 1980s, he argued, when the devices will begin to replace existing equipment. Cost savings in running the technology will lead to its adoption by the consumer with little or no encouragement from the givernment, he argues. "We have found that it is astonishingly easy to save energy" said Mr Leach. "We began this work as energy pessimists, but now we are optimists".

Many of the measures are emerging as a result of the 1973 oil crisis, says the report, when it became fashionable as well as expedient to consider ways of saving energy. The effect of this work is mostly yet to come. The Royal Institute of British Architects, for example, has enthusiastically adopted conservation, an attitude which has already resulted in buildings using half as much energy as before for only a 2 to $3 \%$ cost penalty, but building stock is replaced only slowly. In the home, lights, cookers, and heaters will soon enjoy "very substantial increases in efficiency". Small-scale heat pumps, such as the one being designed by the Gas Boards, are "at an advanced stage" and will make a dramatic impact. The motor industry is designing cars with a $50 \%$ reduction in fuel consumption. Industry uses $40 \%$ of primary energy, "but a large proportion of that is in heating poorly insulated buildings, where strict regulation is on the way" says Gerald Foley, one of the team that produced the report. Indeed the government has already adopted measures which will improve industrial conservation. "The result is that all across the board there is slack" said $\mathrm{Mr}$ Leach. "For example, we predict a need for only $26-30 \mathrm{GW}$ by 2000 , whereas the DOEn assumes $83 \mathrm{GW}$. Quite clearly there is no need for nuclear; we have assumed $4 \frac{1}{2}$ to $6 \frac{1}{2} \mathrm{GW}$ to keep the industry in business. The breeder reactor could be postponed indefinitely." Even renewable sources were not strictly necessary: the report assumes 4-6 million tonnes of coal equivalent produced in 2000 from alternative sources, compared with 10 in the DOEn projection.

The report may, however, have assumed unrealistic substitution rates. The most uncertain element may be the cost of the new technology, and of

\section{Britain's energy optimist}

Gerald Leach, author of $A$ low energy strategy for the UK (see above), may see himself as an energy optimist-but the Financial Times last week saw it differently. Thinking no doubt of the markets lost to the energy supply industry, the subeditor had headlined the story about Leach's report "Bleak forecast for UK energy". But Gerald Leach's interests do not lie with big business.

Gerald Leach is 44, and left science writing and broadcasting (for the BBC and the Observer) in 1972. At the Observer he had become interested in the works of Commoner and Ehrlich, and had accumulated "shelves of fascinating books with no time to read them. As a journalist I felt I was skating over an ocean." Then he met a representative of the Ford Foundation at the Stockholm environment conference, cheque book

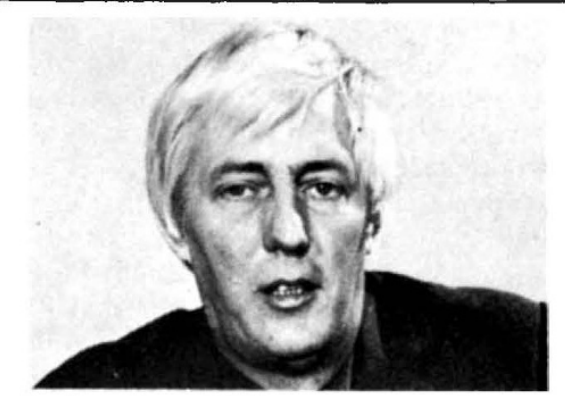

in hand, and his new career began.

He produced a series of reports for various bodies on energy matters, including Energy and Food Production (for IIED), Fuel conservation: options for aviation (for OECD), Nuclear energy balances in a world with ceilings (for IIED), and gave evidence on energy futures to the Windscale inquiry on reprocessing. He defended "Limits to growth" at the Royal Society, did "a big splash" in the Observer; but "I began to feel uncomfortable. Early on he realised the importance of "saturation" effects-such as a ceiling on the number of cars, or the temperature of a house, or conservation. Growth might limit itself.

"Early in 1976 I'd finished a project and I went down to Her Majesty's Stationery Office to read all the government reports on energy. There turned out to be only 4 pages on futures." But the US was much further ahead. "My first task was to convince the Ford Foundation that we were so far behind". Then he got the grant, and the study was under way under the wing of the International Institute for the Environment and Development. "The original proposal to Ford was on alternative sources with a bit of conservation" said Leach. "Then we began to feel strongly about disaggregation", calculating energy futures by adding up all possible uses rather than using macroeconomic trends. It also emerged that previous reports were unduly moderate on conservation. The result was the low energy prediction just published. 